\title{
Effect of chronic airflow limitation on resting oxygen consumption
}

\author{
C Lanigan, J Moxham, J Ponte
}

\begin{abstract}
The work of breathing in patients with severe chronic airflow limitation is increased even at rest but little is known about the magnitude of this increase. Resting oxygen consumption $\left(\mathrm{V}_{2}\right)$, carbon dioxide production $\left(\mathrm{V}_{\mathrm{CO}_{2}}\right)$, and respiratory quotient (RQ) were measured in 13 patients with severe chronic airflow limitation (mean FEV 0.781 , vital capacity 2.11 ) and compared with those of 13 age, weight, and height matched control subjects. Whereas mean RQ was the same in the two groups $(0 \cdot 82)$, mean $\mathrm{VO}_{2}$ and $\dot{\mathrm{V}} \mathrm{CO}_{2}$ were higher in the patients $\left(+18 \mathrm{ml} \mathrm{min}^{-1}\right.$ and $+15 \mathrm{ml}$ $\min ^{-1}$ respectively). When $\dot{V}_{2}$ was standardised for body surface area it was $10.9 \%$ higher in the patients $(p<0.05)$. If the increased resting $\dot{V}_{2}$ in these patients were solely due to increased activity of the respiratory muscles, it would represent a fourfold increase in the oxygen cost of breathing.
\end{abstract}

The diaphragm accounts for most of the work of ventilation during quiet breathing. ${ }^{1}$ In patients with chronic airflow limitation additional energy is expended throughout the breathing cycle, most of which is borne by the inspiratory muscles. ${ }^{2}$ These patients may also have raised energy requirements because of a hyperkinetic circulation, increased blood viscosity, shifts in the haemoglobin dissociation curve, hypoxia, and increased shunt and dead space. ${ }^{3}$ Some of the increased work results from the need to generate larger subatmospheric pressures to expand the thoracic cage ${ }^{4}$ and from the loss of mechanical efficiency of the diaphragm. ${ }^{5}$

Chronic airflow limitation causes a disproportionate increase in total oxygen consumption $\left(\mathrm{V}_{2}\right)$ for a given minute ventilation during exercise. ${ }^{67}$ Evidence for an increased energy expenditure at rest is less convincing. Consequently we undertook a prospective controlled study of resting $\dot{\mathrm{V}}_{2}$, carbon dioxide production $\left(\dot{\mathrm{V}}_{2}\right)$, and respiratory quotient $(\mathrm{RQ})$ in chronic airflow limitation.

\section{Methods}

PATIENTS AND CONTROL SUBJECTS

Thirteen patients (nine of them male)-mean (SD) age $64(6.8)$ years, weight $61(15 \cdot 6) \mathrm{kg}$, height $1.67(0.1) \mathrm{m}$, body surface area 1.67
$(0 \cdot 19) \mathrm{m}^{2}$-were recruited, after informed consent had been obtained and with the approval of the hospital ethics committee, from the chest clinics at King's College and Dulwich Hospitals. They had moderate to severe airflow limitation with minimal reversibility and large lung volumes with reduced carbon monoxide transfer (table). Control subjects consisted of 13 healthy, non-smoking volunteers (six male), mean age 53 (16) years, weight $65(12.5) \mathrm{kg}$, height $1.67(0.12) \mathrm{m}$, and body surface area $1 \cdot 72(0 \cdot 12) \mathrm{m}^{2}$.

\section{EXPERIMENTAL PROCEDURE}

Resting $\dot{\mathrm{VO}}_{2}, \dot{\mathrm{VCO}}_{2}$, and RQ were measured by an open canopy technique with a mass spectrometer (Airspec Ltd). ${ }^{8}$ The subject's head and chest were enclosed in a clear chamber, from which gases were exhausted at a set rate of 80 to $901 \mathrm{~min}^{-1}$ through a mixing box to which argon (Ar, $250 \mathrm{ml} \mathrm{min}^{-1}$ ) was added as a tracer for measurement of flow. The fractional differences between oxygen and carbon dioxide in air and in the outflow from the chamber, measured at six second intervals, were multiplied by flow through the system to produce $\dot{\mathrm{VO}}_{2}, \dot{\mathrm{V}} \mathrm{CO}_{2}$, and RQ $\left(\dot{\mathrm{VCO}}_{2} / \dot{\mathrm{VO}}_{2}\right)$. The resolution, tested by methanol combustion, was $8 \mathrm{ml} \mathrm{min}^{-1}$ for $\dot{\mathrm{VO}}_{2}$ and $6 \mathrm{ml} \mathrm{m^{-1 }}$ for $\dot{\mathrm{V}} \mathrm{CO}_{2}$.

Patients' medication was unaltered; all subjects had at least 30 minutes' rest within the chamber before the study started and listened to music throughout the 20 minutes' continuous gas exchange measurement (200 data points) that followed.

\section{DATA ANALYSIS}

Gas analysis was corrected for instrument drift and methanol combustion tests and converted to STPD. The mean and SD for two consecutive 10 minute periods were calculated, and the lower of the two subsequently included in the analysis. $\mathrm{VO}_{2}$ values were standardised for body surface area (BSA) and calculated as follows':

Log BSA $=\log$ weight $\times 0.425+\log$ height $\times 0.725+1.8564$.

Resting energy expenditure (kJ/day) was compared with predicted values ${ }^{10}$ on the basis of an oxygen equivalent of $4.83 \mathrm{~kJ} / \mathrm{ml}$. Differences between groups were analysed by means of the Wilcoxon signed rank test $(p<0.05)$.

\section{Results}

There were more men in the patient group, but there were no significant differences in terms of

\author{
Dr J Ponte, King's College \\ Hospital, London SE5 9RS \\ Accepted 16 January 1990 \\ Anaesthesia \\ Thoracic Medicine \\ Hospital, College \\ J Moxham
}


Mean pulmonary function data for patients*

\begin{tabular}{|c|c|c|c|c|c|c|}
\hline \multirow[b]{2}{*}{ 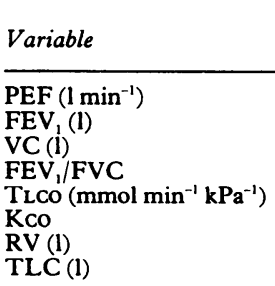 } & \multicolumn{2}{|l|}{ Initial } & \multicolumn{2}{|c|}{$\begin{array}{l}\text { After } \\
\text { bronchodilator }\end{array}$} & \multicolumn{2}{|c|}{$\%$ predicted } \\
\hline & $\begin{array}{c}170 \\
0 \cdot 78 \\
2 \cdot 1 \\
38 \\
4 \cdot 5 \\
1 \cdot 3 \\
5 \cdot 1 \\
7 \cdot 3\end{array}$ & $\begin{array}{c}(93.5) \\
(0.36) \\
(0.6) \\
(14.9) \\
(1.79) \\
(0.42) \\
(2.0) \\
(2.3)\end{array}$ & $\begin{array}{l}180 \\
0 \cdot 83 \\
2 \cdot 4 \\
35\end{array}$ & $\begin{array}{c}(94.7) \\
(0.36) \\
(0.5) \\
(12.4)\end{array}$ & $\begin{array}{r}41 \\
31 \\
62 \\
55 \\
57 \\
88 \\
267 \\
139\end{array}$ & $\begin{array}{l}(21 \cdot 2) \\
(11 \cdot 3) \\
(15 \cdot 6) \\
(21 \cdot 5) \\
(22 \cdot 2) \\
(25 \cdot 3) \\
(90 \cdot 1) \\
(37 \cdot 6)\end{array}$ \\
\hline
\end{tabular}

*0, predicted-(initial value/predicted value) ${ }^{\circ}{ }_{0}$; values represent mean (SD) for 13 patients except for the last four variables, where four patients were unable to perform the tests; and
ond except for the last four variables, where four patie
results were not available for two further patients.

results were not available for two further patients. PEF-peak expiratory flow rate; FEV - forced expiratory volume in the first second;
VC-"slow" vital capacity; TLCo-carbon monoxide transfer factor; Kco-carbon monoxide transfer coefficient in litres (BTPS) $\mathrm{min}^{-1} \mathrm{kPa}^{-1} 1 \mathrm{VA}^{-1} ; \mathrm{RV}$-residual volume; TLC-total lung capacity.

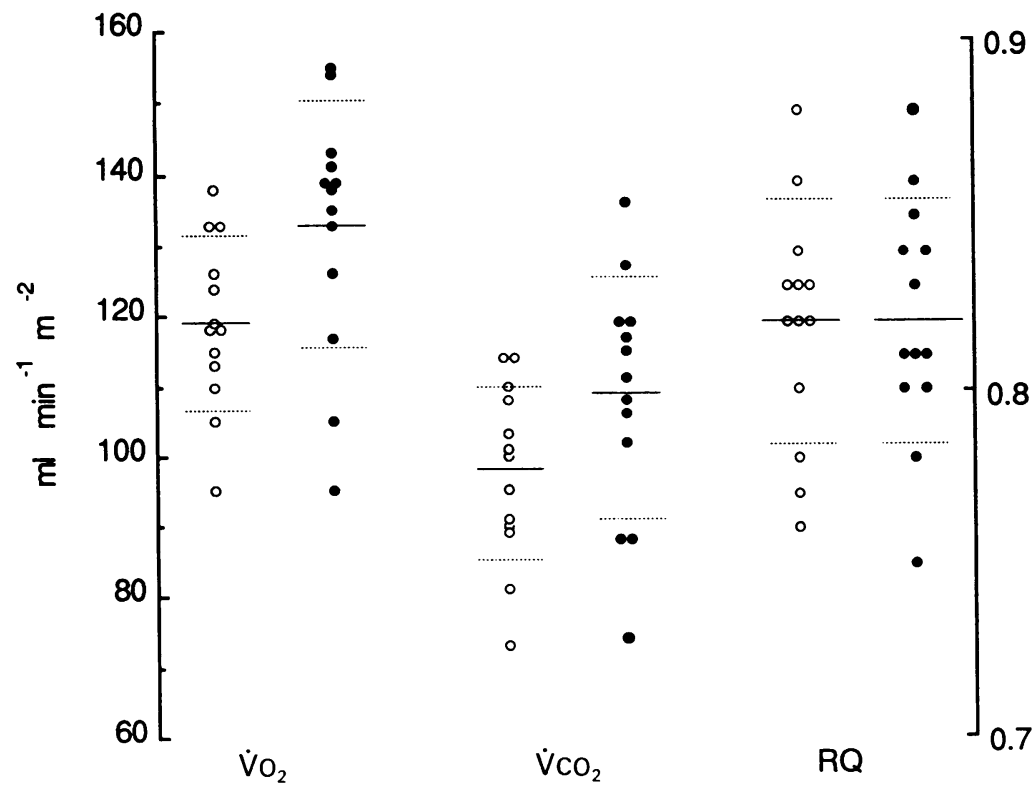

Resting gas exchange in 13 patients with chronic airflow limitation (closed circles) and 13 controls (open circles). Means are horizontal continuous bars and standard deviations horizontal interrupted bars.

\section{Discussion}

Although numbers were small the difference in $\dot{\mathrm{VO}}_{2}$ and $\dot{\mathrm{VCO}}_{2} / \mathrm{BSA}$ between the groups is likely to be real and of considerable clinical interest, as it may largely reflect the difference in the metabolic cost of breathing between the two groups. If the normal cost of breathing is about $3^{\circ}{ }_{0}$ of total $\dot{\mathrm{VO}}_{2}$ (that is, $<8 \mathrm{ml} \mathrm{min}{ }^{-1}$ ), ${ }^{11}$ the cost of breathing in our patients was about $24 \mathrm{ml}$ $\mathrm{min}^{-1}$-four times the normal value, representing $10 \cdot 8^{\circ}{ }_{0}$ of total $\dot{\mathrm{Vo}}_{2}$. At least three other factors in addition to those listed in the introduction might have influenced the result.

Somatometric differences Large scale studies of resting energy expenditure have shown that $\dot{\mathrm{V}} \mathrm{O}_{2}$ declines with age, increases with weight, height, and body surface area, and is lower in women than men. ${ }^{12}$ The group differences were too small to account for the differences in $\mathrm{VO}_{2}$ and $\mathrm{VCO}_{2}$ after normalisation for body surface area. Although there were more men in the patient group, separate analysis of the data for men still showed a higher mean $\mathrm{Vo}_{2} / \mathrm{BSA}$, the difference being $23 \mathrm{ml} \mathrm{min}^{-1}(\mathrm{p}<0.05)$.

Drug treatment Patients were in a stable clinical condition but their drug treatment included beta agonists, methyl xanthines and corticosteroids, all potentially capable of increasing $\mathrm{VO}_{2}$. The precise influence of these drugs on $\mathrm{Vo}_{2}$ was not measured because halting treatment might have exacerbated the condition, but bronchodilator treatment itself might have reduced the work of breathing. The values of $\dot{\mathrm{VO}}_{2}$ and $\dot{\mathrm{V}} \mathrm{CO}_{2}$ obtained probably reflected the "best case" ventilatory conditions.

Acute hyperventilation Placing dyspnoeic patients inside a chamber could have provoked hyperventilation and would have caused the $\mathrm{RQ}$ to rise. Acclimatisation minimised this effect as no individual $R Q$ exceeded $0 \cdot 88$, and the average $R Q$ was identical and normal at $0 \cdot 82^{13}$ for both groups.

The reliability of our method of measuring $\dot{\mathrm{VO}}_{2}$ and $\dot{\mathrm{V}} \mathrm{CO}_{2}$ was confirmed by the close agreement found between measured and predicted resting energy expenditure in the control subjects. ${ }^{10}$ The lack of correlations between $\mathrm{Vo}_{2} / \mathrm{BSA}$ and indices of airways obstruction is not surprising given the complex relation between lung mechanics and the work of breathing, the small numbers studied, and the relatively uniform severity of the airflow obstruction. We decided not to monitor minute or tidal ventilation because of the inevitable artefact introduced by the recording method, which could have produced different weighting in patients and in control subjects. ${ }^{14}$ Previous authors ${ }^{15}$ have reported a $30 \%$ increase in minute volume when a facemask is worn by normal subjects and a $14 \%$ increase when a mouthpiece and noseclips are used. Indirect methods of measuring tidal ventilation (for example, magnetometry and inductive plethysmography), though adequate for detecting relative changes within subjects, are not suitable for measuring absolute differences between subjects.

One other group has found an increased metabolic rate in patients with chronic airflow obstruction. ${ }^{16}$ Although they used a similar 
open canopy method and control subjects, the data obtained by these authors are not comparable to ours as they studied only malnourished patients. Another group specifically studied resting $\mathrm{VO}_{2}$ in 43 patients with chronic airflow limitation ${ }^{17}$ but normal control subjects were not studied. Several other studies have obtained $\mathrm{Vo}_{2}$ data from smaller groups of patients (up to 10) before exercise or rebreathing tests. ${ }^{18-21}$ All these studies made use of mouthpieces, noseclips or face masks, which might have affected the results. Nevertheless, all authors have reported increases in metabolic rate, which was $8 \cdot 5-20 \%$ above predicted values.

In conclusion, our results indicate that the resting $\dot{\mathrm{VO}}_{2}$ in patients with chronic airflow limitation, normally nourished and undisturbed by measuring appliances, is about $10 \%$ higher than in normal subjects. If this increase in $\dot{\mathrm{VO}}_{2}$ were solely due to greater respiratory muscle work, then the patients had a fourfold increase in the oxygen cost of breathing at rest.

1 Mead J, Loring S. Analysis of volume displacement and length changes of the diaphragm during breathing. $J A p p l$ Physiol 1982;53:750-5.

2 Rochester DF, Arora MMS, Braun NM, Goldberg SK. The respiratory muscles in chronic obstructive pulmonary disease (COPD). Bull Eur Physiopathol Respir 1979;15: 951-75.

3 Brown HV, Wasserman $\mathrm{K}$. Exercise performance in chronic obstructive pulmonary disease. Med Clin North Am 1981; obstructive
$65: 525-47$.

4 Kimball WR, Leith DE, Robins AG. Dynamic hyperinflation and ventilator dependence in chronic obstructive pulmonary disease. Am Rev Respir Dis 1982;126:991-5.
5 Rochester DF, Braun NM. Determinants of maximal inspiratory pressure in chronic obstructive pulmonary disease. Am Rev Respir Dis 1985;132:42-7.

6 Jones NL. Pulmonary gas exchange during exercise in patients with chronic airways obstruction. Clin Sci 1966; 31:39-50.

7 Jones NL, Jones G, Edwards RHT. Exercise tolerance in chronic airways obstruction. Am Rev Respir Dis 1971;103: 477-91.

8 Hughes SW, Lanigan C, Moxham J, Ponte J. Continuous measurement of oxygen consumption and carbon dioxide measurement of oxygen consumption and carbon dio
production in man. J Physiol (Lond) 1985;371:233P.

9 DuBois D, DuBois EF. A formula to estimate the approximate surface area if height and weight be known. Arch Intern Med 1916;17:863-71.

10 Harris JA, Benedict FG. A biometric study of basal metabolism in man. Washington DC: Carnegie Institute of Washington, 1919:279.

11 Lanigan C. The respiratory muscle pump. MD thesis, University College, Dublin, 1988

12 Schofield WN, Schofield C, James WP. Predicting basal metabolic rate, new standards and review of previous work. Hum Nutrit Clin Nutrit 1985;39C:5-41.

13 Consolazio CF, Johnson RE, Pecora LJ. Physiological measurements of metabolic function in man. New York: measurements of metabo

14 Douglas NJ, White DP, Weil JV, Zwillich CW. Effect of breathing route on ventilation and ventilatory drive Respir Physiol 1983;51:209-18.

15 Askanazi J, Silverberg PA, Forster RJ, Hyman AI, Milic Emili J, Kinney JM. Effects of respiratory apparatus on breathing pattern.J Appl Physiol 1980;48:577-80

16 Goldstein MS, Askanazi J, Weissman C, Thomashow B Kinney JM. Energy expenditure in patients with chronic obstructive pulmonary disease. Chest 1987;91:222-4.

17 Moore JA, Angelillo VA. Energy expenditure in chronic obstructive lung disease. Chest 1988;94:1260-3.

18 Donahoe M, Rogers RM, Wilson DO, Pennock BE. Oxygen consumption of the respiratory muscles in normal and in malnourished patients with chronic obstructive pulmalnourished patients with chronic obstructive pul-
monary disease. Am Rev Respir Dis 1989;140:385-91.

19 Wehr KL, Johnson RL, Prengler A. Maximal oxygen consumption in patients with lung disease. J Clin Invest 1976;58:880-90.

20 Pardy RL, Roussos C. Endurance of hyperventilation in patients with chronic airflow limitation. Chest 1983;83 744-50.

21 Stewart RI, Lewis CM. Arterial oxygenation and oxygen transport during exercise in patients with chronic obstructive pulmonary disease. Respiration 1986;49:161-9. 